\title{
A Case of COVID-19-Related Thrombocytopenia and Leukopenia in an Adolescent with Mild Symptoms
}

\author{
Lydia Kossiva ${ }^{1}$, Athanasios Thirios ${ }^{1}$, Eleni Panagouli ${ }^{1}{ }^{\circledR}$, Alexandros Panos ${ }^{1}$, Stavroula Lampidi ${ }^{1}$, \\ Flora Bacopoulou ${ }^{2}{ }^{-}$, Maria Tsolia ${ }^{1}$ and Artemis Tsitsika ${ }^{1, *}$ \\ 1 2nd Department of Pediatrics, “P. \& A. Kyriakou” Children's Hospital, School of Medicine, \\ National and Kapodistrian University of Athens, 11527 Athens, Greece; lydiakossiva@hotmail.com (L.K.); \\ athirios@med.uoa.gr (A.T.); elenpana@med.uoa.gr (E.P.); alxpanos@gmail.com (A.P.); \\ stavroul.lab@gmail.com (S.L.); mariantsolia@gmail.com (M.T.) \\ 2 Center for Adolescent Medicine and UNESCO Chair Adolescent Health Care, First Department of Pediatrics, \\ "Agia Sophia" Children's Hospital, School of Medicine, National and Kapodistrian University of Athens, \\ 11527 Athens, Greece; bacopouf@hotmail.com \\ * Correspondence: info@youth-health.gr; Tel./Fax: +30-2107710824
}

\section{check for} updates

Citation: Kossiva, L.; Thirios, A.; Panagouli, E.; Panos, A.; Lampidi, S.; Bacopoulou, F.; Tsolia, M.; Tsitsika, A. A Case of COVID-19-Related

Thrombocytopenia and Leukopenia in an Adolescent with Mild Symptoms. Children 2021, 8, 509. https://doi.org/10.3390/ children 8060509

Academic Editor: Johannes N. Van den Anker

Received: 1 April 2021

Accepted: 11 June 2021

Published: 16 June 2021

Publisher's Note: MDPI stays neutral with regard to jurisdictional claims in published maps and institutional affiliations.

Copyright: (c) 2021 by the authors. Licensee MDPI, Basel, Switzerland. This article is an open access article distributed under the terms and conditions of the Creative Commons Attribution (CC BY) license (https:// creativecommons.org/licenses/by/ $4.0 /)$.

\begin{abstract}
Since the beginning of the COVID-19 pandemic, there have been numerous reports and reviews on the complications caused by the disease, analyzing the acute and chronic consequences. The main symptoms of SARS-CoV-2 are dry cough, fever, and fatigue. COVID-19 appears to affect all systems, including renal, cardiovascular, circulatory, and respiratory systems, causing chronic obstructive pulmonary disease. We report on a 14-year-old male adolescent, who presented with thrombocytopenia (platelet count $92 \times 10^{9} / \mathrm{L}$ ) and leukopenia (white blood count $4.2 \times 10^{3} / \mu \mathrm{L}$ ) that was observed two months ago. Ten days before the first blood test, a viral infection with nasal congestion and runny nose was reported, without other accompanying symptoms. Viral antibodies screening revealed positivity for all the three specific COVID-19 antibodies. Further haematological evaluation with bone marrow aspiration revealed non-specific dysplastic features of the red cell and megakaryocyte progenitors. Although haematological alterations due to COVID-19 infection are available from adult patients' reports, the effect of COVID-19 infection in the pediatric population is underestimated and this is the first case with such haematological involvement. Noteworthy, in the current case, the impact of the COVID-19 infection was not related to the severity of the disease, as the symptoms were mild. In similar cases, bone marrow aspiration would not be performed as a part of routine work-up. Thus, it is important when evaluating pediatric patients with COVID-19 infection to search and report those alterations in order to better understand the impact and the spectrum of clinical manifestations of the specific viral infection in children and adolescents.
\end{abstract}

Keywords: COVID-19; leucopenia; platelet count; bone marrow; myelodysplastic syndromes

\section{Introduction}

SARS-CoV-2 belongs to the genus $\beta$ of the coronavirus family. It is a new coronavirus related to severe acute respiratory syndrome (SARS-CoV) and the cause of the current pandemic. SARS-CoV-2 shares the same clinical symptoms with the other coronaviruses but it has the ability to bind to angiotensin-converting enzyme 2 (ACE-2) receptors 10-20 times that of other coronaviruses [1]. Since the beginning of the COVID-19 pandemic, there have been numerous reports and reviews on the complications caused by the disease, analyzing the acute and chronic consequences that have arisen. The main symptoms of SARS-CoV-2 are dry cough, fever, and fatigue. COVID-19 appears to affect all systems, including renal, cardiovascular, circulatory, and of course, respiratory, causing chronic obstructive pulmonary disease [2].

A severe form of the SARS-CoV-2 disease in adult patients is a hyperinflammatory condition that affects all systems and may lead to multi-organ failure and death. Among 
pediatric COVID-19-infected patients, a small percentage develops a severe entity termed Multisystem Inflammatory Syndrome in Children (MIS-C), which is a hyper-inflammatory process due to viral infection and progresses to multiple organ failure, resembling the same catastrophic inflammatory reaction observed in adults. Elevated inflammatory biomarkers are included in the diagnostic criteria for MIS-C [3]. Laboratory abnormalities in children with MIS-C more closely represent those seen in adults, with lymphopenia, and elevations of inflammatory biomarkers, D-dimer, cardiac troponin, and natriuretic peptides being commonly reported findings [4-6]. The most common hematological findings in patients with COVID-19 include reduced lymphocyte count, while the platelet count differs according to the severity of the disease as well as the total number of the white blood cell count [7-9]. Severe lymphopenia was linked to more severe disease compared to milder lymphopenia, although leukocytosis was referred as an indication of severe inflammation process [10].

Immune thrombocytopenia (ITP) is defined as a platelet count $<100 \times 10^{9} / \mathrm{L}$. Petechiae or purpuric rashes are often present. ITP could be either primary or secondary. The most frequent causes of secondary ITP are several viral infections, such as varicella zoster virus, cytomegalovirus, hepatitis B/C viruses, or human immunodeficiency virus and, most recently, SARS-CoV-2 [11]. The majority of ITP cases, secondary to COVID-19, were reported three or four weeks after the onset of the illness in adult patients, while only a few reports on pediatric patients reported thrombocytopenia during the acute or the convalescent phase of the disease [12]. Changes of the red blood cell count during COVID19 infection are reported in a small percentage of patients. In detail, lower hemoglobin levels along with a decrease of the mean corpuscular volume (MCV) are the main findings in some cases [13,14]. Only a handful of studies of the pediatric COVID-19 patients are available as far as hematological alterations are concerned.

We report on a case of secondary ITP along with borderline leukopenia and non- specific dysplastic features of the bone marrow, in a previous healthy 14-year-old male adolescent after a mildly symptomatic COVID-19 infection. Diagnosis of such cases is of high importance for the better understanding of the spectrum of COVID-19-infection consequences.

\section{Case Presentation}

A 14-year-old male adolescent attended the Adolescent Health Unit due to thrombocytopenia and leukopenia that was observed two months ago during an investigation for acute abdominal pain. A viral infection with nasal congestion and runny nose was reported ten days before the manifestation of the abdominal pain and the first haematological evaluation with full blood count (FBC: Hb 11.4 gr/dL (14-18), MCV 68 fL (79-98), WBC 4.2 cells $/ \mu \mathrm{L}(4.0-10.0)$, PLT $\left.92 \times 10^{9} / \mathrm{L}\right)$.

The patient was reported previously healthy, with a history of tonsillectomy and adenoidectomy in infancy. He was the second child of non-consanguineous parents, born full-term with a normal perinatal period. He was fully vaccinated for his age, with normal weight and height (body mass: $73.5 \mathrm{~kg}$, 90th percentile—height: $184 \mathrm{~cm},<97$ percentile—BMI: $21.7 \mathrm{~kg} / \mathrm{m}^{2}$, 50 percentile).

According to the family history, his mother was completely healthy, while the father reported bronchial asthma, paroxysmal atrial fibrillation, and thyroidectomy nine years ago due to papillary thyroid cancer. No autoimmune diseases were mentioned in the family.

On admission in the Adolescent Health Unit, the adolescent was in excellent condition, with normal vital signs for his age (BP: 127/60 mmHg, HR: 78/min). The clinical examination revealed only a few petechiae on the back and the left clavicle. He underwent a thorough laboratory evaluation with complete blood count, biochemical markers, and extended viral and autoimmune panel screening. Thyroid function was also evaluated. The abdominal ultrasound and chest $X$-ray were both normal. He was tested negative for acute COVID-19 (PCR SARS-CoV-2) infection using a molecular (PCR) test, while the antibody titer against COVID-19 was sent and positive IgA, IgG, and IgM antibodies against COVID-19 were found (Table 1). 
Table 1. Initial laboratory evaluation.

\begin{tabular}{|c|c|}
\hline Immunoglobulings & Normal Values (mg/dL) \\
\hline $\operatorname{IgG}$ & $1150(863-1847)$ \\
\hline $\operatorname{Ig} \mathrm{A}$ & $128(70-400)$ \\
\hline $\operatorname{IgM}$ & $100(40-289)$ \\
\hline $\mathrm{C} 3$ & $116(90-180)$ \\
\hline $\mathrm{C} 4$ & $16(13-75)$ \\
\hline \multicolumn{2}{|l|}{ Virology panel: } \\
\hline Human Herpes Virus 6 (HHV6) & $\operatorname{IgM}(-), \operatorname{IgG}(-)$ \\
\hline Mycoplasma pneumoniae & $\operatorname{IgM}(-), \operatorname{IgG}(-)$ \\
\hline Herpes Simplex 1,2 (HSV1,2) & $\operatorname{IgM}(-), \operatorname{IgG}(-)$ \\
\hline Adenovirus & $\operatorname{IgM}(-), \operatorname{Ig} G(+)$ \\
\hline Parvo B19 & $\operatorname{IgM}(-), \operatorname{IgG}(-)$ \\
\hline Anti HBsAg & $(-)$ \\
\hline Anti-HBs & $(+)$ \\
\hline Anti-HCV & $(-)$ \\
\hline Human Immunodeficiency virus (HIV) & $(-)$ \\
\hline Toxoplasma gondii & $\operatorname{IgM}(-), \operatorname{IgG}(-)$ \\
\hline Cytomegalovirus (CMV) & $\operatorname{IgM}(-), \operatorname{IgG}(-)$ \\
\hline Epstein -Barr virus (EBV) & $\operatorname{IgM}(-), \operatorname{IgG}(+)$ \\
\hline SARs-COV-2 (PCR) & negative \\
\hline SARs-COV-2 abs * & POSITIVE \\
\hline $\operatorname{Ig} \mathrm{A}$ & 2.48 (negative < 0.8 ) \\
\hline IgG & 1.32 (negative $<0.8$ ) \\
\hline $\operatorname{IgM}$ & 1.34 (negative < 0.28 ) \\
\hline Ferritin & $32.7 \mathrm{ng} / \mathrm{ml}(4.6-274)$ \\
\hline B12 & $652 \mathrm{pg} / \mathrm{ml}(187-883)$ \\
\hline TSH & $1.27 \mathrm{mIU} / \mathrm{ml}(0.35-4.94)$ \\
\hline $\begin{array}{l}\text { Bleeding screening panel: (PT, aPTT, INR, } \\
\text { Fibrinogen, D-dimers) }\end{array}$ & normal \\
\hline Direct anti-globulin test: negative & negative \\
\hline $\begin{array}{l}\text { Immunophenotype of lymphocyte } \\
\text { subpopulation of peripheral blood: }\end{array}$ & $\begin{array}{l}(\mathrm{CD} 3+) 72.1 \% \\
(\mathrm{CD} 4+) 40.5 \% \\
(\mathrm{CD} 8+) 31.8 \%\end{array}$ \\
\hline
\end{tabular}

* Enzyme linked Immunosorbent Assay (ELISA).

The alterations of two blood cell lines (leukopenia and thrombocytopenia) along with microcytosis $(2+)$, hypochromy $(1+)$, poikilocytosis $(1+)$ of the red cell line and the age of the patient dictated further haematological and immunological evaluation. The bone marrow aspiration revealed that megakaryocytes were still present in normal numbers and producing platelets, while a small percentage of megakaryocyte progenitors displayed dysplastic features (micromegakaryocytes) along with mild non-specific dysplastic features of the erythrocyte progenitors. A small degree of non-specific hemophagocytosis was also present. A detailed evaluation towards myelodysplastic syndromes was performed with bone marrow karyotype, which was normal $(46, \mathrm{XY})$, and fluorescent in situ hybridization (FISH) of the bone marrow, which was negative for monosomy 7/7q31del, 17, 5/5q31del, trisomy 8 , and loss of p53. Fanconi anemia was excluded based on a negative chromosomal fragility screening test. A detailed and immunological work-up with immunoglobulin 
levels (IgG, IgA, IgM), immunophenotype of the peripheral lymphocyte subpopulations, C3, C4, and anti-nuclear and anti-ds DNA antibodies was performed and no indication of either immunodeficiency or autoimmune disease was found. The viral screening revealed positivity for all three specific COVID-19 antibodies (Table 1). The most possible cause of the ITP manifestation along with leukopenia and bone marrow dysplasia in our patient was considered to be a previous infection by SARS-CoV-2, probably the viral infection mentioned a few weeks ago. He did not receive any treatment and was discharged in excellent clinical condition after the completion of the clinical and laboratory evaluation. During follow-up, the adolescent remained asymptomatic and the platelet count was constantly rising while the white blood cell counts were still marginally low. Three months later (five months from the initial FBC) he is still leukopenic with borderline platelet number (Table 2).

Table 2. Full blood count (FBC) on admission, discharge, and 3 months later.

\begin{tabular}{|c|c|c|c|}
\hline Laboratory Tests & $\begin{array}{c}\text { Admission to the Adolescent } \\
\text { Health Unit }\end{array}$ & $\begin{array}{c}\text { Admission to the Adolescent } \\
\text { Health Unit }\end{array}$ & $\begin{array}{l}3 \text { Months Later (Five Months } \\
\text { from the Initial FBC) }\end{array}$ \\
\hline \multirow{2}{*}{$\mathrm{WBC}(/ \mu \mathrm{L})$} & 3.400 & 3900 & 4100 \\
\hline & $\begin{array}{l}\text { PMN:45.3\% (absolute number: } \\
\text { 1533) LYM: } 47.7 \% \text { (absolute } \\
\text { number: } 1621 \text { ) MONO: } 4.9 \%\end{array}$ & $\begin{array}{l}\text { PMN: } 44 \% \text { (absolute number: } \\
\text { 1716) LYM: } 46 \% \text {, (absolute } \\
\text { number: 1794) MONO: } 6 \%\end{array}$ & $\begin{array}{l}\text { PMN: } 39.3 \% \text { (absolute } \\
\text { number: } 1600 \text { ) LYM: } 53.1 \% \text {, } \\
\text { (absolute number: } 2200 \text { ) } \\
\text { MONO: } 5.4 \%\end{array}$ \\
\hline $\mathrm{Hb}(\mathrm{g} / \mathrm{dL})$ & 12.3 & 11.6 & 12.1 \\
\hline MCV (fL) & 64 & 65.2 & 67.3 \\
\hline $\operatorname{PLT}(/ \mu \mathrm{L})$ & 86,000 - platelet anisocytosis & 130,000 & 112,000 \\
\hline
\end{tabular}

WBC: white blood cells, Hb: hemoglobin, PLT: platelets, PMN: polymorphonuclear leukocytes, LYM: lymphocytes, MCV: mean corpuscular volume, MONO: monocytes.

\section{Discussion}

Our patient, even barely symptomatic at the beginning and without overt COVID19 infection, exhibited thrombocytopenia, leukopenia, marginal lymphopenia, and nonspecific dysplastic features in bone marrow aspiration. Based on the existing literature, only a few reports are available on haematological alterations due to COVID-19 infection, especially in children. This may be due to the fact that children are less vulnerable to severe disease, needing hospitalization, or their immature immune system reacts in a different way compared to adults. According to reports from adult patients with SARSCoV-2, leukocytosis, lymphopenia, and various degrees of thrombocytopenia were linked to severe disease. Immune thrombocytopenia (ITP) has been associated with COVID-19 and seems to be an important risk factor for increased morbidity and mortality in those patients [8,11].

Bhattacharjee et al. have performed a systematic review concerning the clinical profile and outcomes of secondary ITP to COVID-19. In a total of 45 cases, the $71 \%$ were adults, aged over $>50$ years, while the $75 \%$ had moderate-to-severe COVID- 19 and only $7 \%$ were asymptomatic. In $21 \%$, ITP was observed about three weeks after the first diagnosis of COVID-19 and in post-recovery period. Only one associated case of death was recorded, due to intracranial hemorrhage and one case of secondary Evans syndrome [11]. Pediatric patients seem to be the minority, as only three cases $(7 \%)$ of secondary ITP have been described. All the cases refer to children over 10 years old, two girls and one 16-year-old boy [15-17]. In two cases, low platelet count was observed after investigating a rash without other symptoms. Both children reported a mild illness before 3 to 4 weeks, the one was linked to COVID-19 and the other one was tested positive [15,17]. The third patient had an ongoing severe COVID-19 infection [16]. All of them received some kind of treatment for the ITP. Another paper from Tiwari et al. reported that 18.2\% of pediatric COVID-19 cases exhibited thrombocytopenia, while in a meta-analysis paper from adult patients, the low platelet count was positively associated with the severity and the mortality of the disease [18]. Our patient had a negative COVID-19 PCR at the time of admission and 
recovered without any treatment. We might hypothesize that the lack of severe symptoms could be the reason for the mild thrombocytopenia. This is not the usual degree of postviral thrombocytopenia attributed to other viruses, but in COVID-19, things might be different. The lower proportion of thrombocytopenia reported in children may be due to the milder clinical course and better prognosis of the disease compared to the adult COVID-19 patients.

Possible mechanisms suggesting the pathogenesis of ITP in COVID-19 disease include the direct infection of bone marrow cells [19]. It is speculated that SARS-CoV-2 decreases primary platelet formation through the inhibition of hematopoiesis in the bone marrow [20]. In detail, the bone marrow may be directly affected by the COVID-19 virus itself through specific receptors (CD13) on the progenitor hematopoietic cells, resulting in decreased platelet formation. Additionally, the virus may produce antibodies that cross-react with specific antigens on the platelet surface, through molecular mimicry, resulting in increased platelet destruction mainly from the macrophages of the spleen [20]. It is also suggested that, following the cytokine storm caused by SARS-CoV-2 infection, primary production of platelets from megakaryocytes decreases [21]. Finally, in overt disease, the increased platelet consumption due to aggregation and microthrombi formation, because of damaged pulmonary endothelial cells, enhances the platelet consumption [20]. The lower proportion of thrombocytopenia reported in children may be due to the milder clinical course and better prognosis of the disease compared to the adult COVID-19 patients.

Among other hemocytometry alterations, the presence of lymphopenia is a wellrecognized finding linked to COVID-19, while leukocytosis is reported as a risk-marker in cases with hyperinflammation [22]. In most viruses, a lymphocytosis is present as a result of infection, while in SARS-CoV-2, infection lymphocyte depletion was noted. Several possible mechanisms for that have been suggested [1,23-25]. In detail, a lower \% of CD4+ and CD8+ T-lymphocyte subpopulations have been described in patients with symptomatic COVID-19 infection. Lymphopenia associated with a low percentage of CD4+ and CD8+ T-lymphocytes returned to normal upon viral clearance [26]. According to a previous report from Lu et al., among 171 children with symptomatic COVID-19 infection, only six $(3.5 \%)$ exhibited lymphopenia, even though in a meta-analysis from Henry et al., the aforementioned finding was much less common $[27,28]$. In a previous report from Qiu $\mathrm{H}$ et al., within a study group of 36 children with mild to moderate disease, $31 \%$ had low lymphocyte numbers and 19\% had leukopenia [29]. In another report among 50 children with COVID-19 infection, 20\% exhibited lymphopenia and $8 \%$ had an elevated number of lymphocytes [30]. Our patient had CD4+ and CD8+ T-lymphocyte subpopulations within normal range for his age but he exhibited a decrease of the total number of leukocytes and a marginally normal absolute number of neutrophils $(1533 / \mu \mathrm{L})$ (Tables 1 and 2$)$.

The presence of leukopenia has been reported in COVID-19 patients. Du et al., referred to severe leukopenia and lymphopenia in symptomatic rather than asymptomatic cases. A different response of the immature immune system in the younger age patients along with the limited data from the pediatric population could explain those findings [24,25]. Yarali et al. reported lymphopenia, neutropenia, and neutrophilia in 30\%, 23.3\%, and 13.3\%, respectively, of the pediatric patients, despite the normal count of the leukocytes [24]. Other studies did not show the same alterations as far as the total number of white blood cells, lymphocytes, and neutrophils is concerned, as even in severe cases, the numbers of the aforementioned cell populations were within normal reference range [31]. A review paper from Kosmeri et al. concluded that the majority of children with COVID-19 infection exhibited normal WBC count and lymphopenia was not as frequently, as in adults, observed, possibly due to milder manifestation of the disease in younger ones [32]. Prognostic factors of the severity of the disease may be established based on the combination of several haematological parameters, such as the lymphocyte to neutrophil ratio, as reported in reports from adult patients [33]. The value of those prognostic factors is the prediction of critical illness in an early stage of the COVID-19 infection. Interestingly, our patient, even though mildly symptomatic, exhibited leukopenia, which was stable during follow- 
up. This is in accordance with a systematic review from Ma $\mathrm{X}$ et al. in which, among 486 hospitalized children, $21 \%$ had leukopenia and most of them had mild disease [34].

As for the red cell line, our patient exhibited mild anemia with low mean corpuscular volume (MCV). He did not have a history of thalassemia trait and his ferritin levels were within normal range (Table 1). In a large study from China among 244 pediatric patients, 193 had symptomatic COVID-19 infection and significantly lower levels of hemoglobin were found [14]. A lower level of hemoglobin has been reported along with a decrease in $\mathrm{MCV}$, while those findings were more consistent in severely ill adult patients [35,36]. Infection by SARS-CoV-2 may directly affect the red cell precursors of the bone marrow either directly through ACE-2 receptors, leading to early apoptosis, or by inhibiting hematopoiesis though cytokine action in severely ill patients due to inflammatory process. A study from Yuan X et al. reported that critically ill patients had higher levels of IL-6, which is a wellrecognized cytokine that affects hematopoiesis. Another possible mechanism of anemia may be due to hemophagocytosis of the red blood cells within the marrow or other sites such as lymph nodes and the spleen. The last mechanism is seen in severe cases and it is linked to high morbidity and mortality [1]. A paper from Liu and Li proposed certain SARS-CoV-2 proteins may interfere with erythropoiesis via attack of the beta chain of hemoglobin, resulting in a decrease of its level [37]. A reduction in hemoglobin could aggravate the respiratory distress syndrome in severely ill patients. In our case, there was no specific hemophagocytosis in the bone marrow and the rest of the diagnostic criteria (lipid profile, ferritin, coagulation panel) were within normal ranges and most of all our patients were asymptomatic and in excellent clinical condition. The non-specific dysplastic features of the red-cell progenitors were characterized as an asynchronous maturation process. Taking into account that the adolescent had absolutely normal complete blood counts in the past, we may hypothesize that COVID-19 infection, even with mild symptoms, might interfere with the normal hematopoiesis, leading to various degrees of anemia and microcytosis, but the exact mechanism of anemia is still obscure.

In our case, the presence of leukopenia with mild lymphopenia, along with thrombocytopenia and bone marrow non-specific dysplastic features of the red and megakaryocyte cell lines in an adolescent without previous hematological problems and in good clinical condition, is reported for the first time. It is noteworthy that three months after the first laboratory evaluation, the boy still has leukopenia and borderline number of platelets (Table 2). At this time, a repeat of the immunophenotype of lymphocyte subpopulations of the peripheral blood was within normal limits for his age. The fact that a rather mild COVID-19 infection caused numerical alterations in two cell lines (platelets and white blood cells) and quantitative and qualitative changes of the red blood cells (mild anemia and microcytosis) should be added to the spectrum of COVID-19 manifestations. It seems that some individuals may be more prone to hematological changes due to COVID-19 infection even if they exhibited mild clinical symptoms. As time passes, new COVID-19related consequences will be added to its spectrum of manifestations. In our case, we may hypothesize that the mild viral infection, probably due to COVID-19 even though the patient was barely symptomatic, was responsible for alterations in all three cell lines of the bone marrow.

Concerning pediatric patients, we may underline that the incidence is underestimated due to the asymptomatic cases of COVID-19 and medical professionals must be aware and include SARS-CoV-2 infection within the panel of viral investigation of any type of haematological newly diagnosed pediatric cases. Even though lymphopenia and ITP are the most commonly reported haematological alterations until now, other haematological manifestations could be linked to COVID-19 infection in the future. Only limited data of the pediatric patients are available and the haematological alterations may be underestimated, as bone marrow aspiration is not a part of routine work-up especially in mild symptomatic cases. Thus, it is important to search and report those alterations during the COVID-19 pandemic as some cases may lead to severe, even life-threating sequelae. Additionally, a 
prognostic score based on classical hemocytometric parameters in pediatric patients may help in early identification of patients under risk for severe disease.

Author Contributions: Conceptualization, M.T. and A.T. (Artemis Tsitsika); methodology, L.K., A.T. (Athanasios Thirios), E.P., S.L. and A.P.; investigation, L.K., A.T. (Athanasios Thirios), A.P., E.P. and S.L.; resources, A.T. (Athanasios Thirios); writing—original draft preparation, A.T. (Athanasios Thirios), E.P., A.P. and S.L.; writing-review and editing, L.K., M.T., F.B. and A.T. (Artemis Tsitsika); supervision, M.T., F.B. and A.T. (Artemis Tsitsika); project administration, F.B. and A.T. (Artemis Tsitsika). All authors have read and agreed to the published version of the manuscript.

Funding: This research received no external funding.

Institutional Review Board Statement: Ethical review and approval were waived for this case study.

Informed Consent Statement: Informed consent has been obtained from the patient's parents to publish this manuscript.

Data Availability Statement: The datasets used in this study are available from the corresponding author.

Conflicts of Interest: The authors declare no conflict of interest.

\section{References}

1. Yuan, X.; Huang, W.; Ye, B.; Chen, C.; Huang, R.; Wu, F.; Wei, Q.; Zhang, W.; Hu, J. Changes of hematological and immunological parameters in COVID-19 patients. Int. J. Hematol. 2020, 112, 553-559. [CrossRef] [PubMed]

2. Lippi, G.; Henry, B.M. Chronic obstructive pulmonary disease is associated with severe coronavirus disease 2019 (COVID-19). Respir. Med. 2020, 167, 105941. [CrossRef] [PubMed]

3. COVID-19-Associated Multisystem Inflammatory Syndrome in Children-United States, March-July 2020 Weekly/August 14, 2020/69(32);1074-1080. Available online: https:/ /www.cdc.gov/mis-c/hcp (accessed on 14 August 2020).

4. Hoang, A.; Chorath, K.; Moreira, A.; Evans, M.; Burmeister-Morton, F.; Burmeister, F.; Naqvi, R.; Petershack, M.; Moreira, A. COVID-19 in 7780 pediatric patients: A systematic review. EClinicalMedicine 2020, 24, 100433. [CrossRef]

5. Feldstein, L.R.; Rose, E.B.; Horwitz, S.M.; Collins, J.P.; Newhams, M.M.; Son, M.B.F.; Newburger, J.W.; Kleinman, L.C.; Heidemann, S.M.; Martin, A.A.; et al. Multisystem Inflammatory Syndrome in U.S. Children and Adolescents. N. Engl. J. Med. 2020, 383, 334-346. [CrossRef] [PubMed]

6. Dufort, E.M.; Koumans, E.H.; Chow, E.J.; Rosenthal, E.M.; Muse, A.; Rowlands, J.; Barranco, M.A.; Maxted, A.M.; Rosenberg, E.S.; Easton, D.; et al. Multisystem Inflammatory Syndrome in Children in New York State. N. Engl. J. Med. 2020, 383, 347-358. [CrossRef]

7. Chen, N.; Zhou, M.; Dong, X.; Qu, J.; Gong, F.; Han, Y.; Qiu, Y.; Wang, J.; Liu, Y.; Wei, Y.; et al. Epidemiological and clinical characteristics of 99 cases of 2019 novel coronavirus pneumonia in Wuhan, China: A descriptive study. Lancet 2020, 395, 507-513. [CrossRef]

8. Bomhof, G.; Mutsaers, P.G.N.J.; Leebeek, F.W.G.; Boekhorst, P.A.W.T.; Hofland, J.; Croles, F.N.; Jansen, A.J.G. COVID-19-associated immune thrombocytopenia. Br. J. Haematol. 2020, 190, e61-e64. [CrossRef]

9. Słomka, A.; Kowalewski, M.; Żekanowska, E. Coronavirus Disease 2019 (COVID-19): A Short Review on Hematological Manifestations. Pathogenes 2020, 9, 493. [CrossRef] [PubMed]

10. Rahman, A.; Niloofa, R.; Jayarajah, U.; De Mel, S.; Abeysuriya, V.; Seneviratne, S.L. Hematological Abnormalities in COVID-19: A Narrative Review. Am. J. Trop. Med. Hyg. 2021, 104, 1188-1201. [CrossRef]

11. Bhattacharjee, S.; Banerjee, M. Immune Thrombocytopenia Secondary to COVID-19: A Systematic Review. SN Compr. Clin. Med. 2020, 2, 2048-2058. [CrossRef]

12. Thompson, S.; Bohnm, M.K.; Mancini, N.; Loh, T.P.; Wang, C.B.; Grimmler, M.; Yuen, K.-Y.; Mueller, R.; Koch, D.; Sethi, S.; et al. IFCC Interim Guidelines on Biochemical/ Hematological Monitoring of COVID-19 Patients. Clin. Chem. Lab. Med. 2020, 58, 2009-2016. [CrossRef] [PubMed]

13. Margekar, S.L.; Margekar, P.; Kumar, A.; Margekar, V.G. Hematological profile in COVID-19, whether it matters in children. Indian J. Med. Spec. 2021, 12, 11. [CrossRef]

14. Xiong, X.; Chua, G.T.; Chi, S.; Kwan, M.Y.; Wong, W.H.; Zhou, A.; Shekd, C.C.; Tung, K.T.S.; Qin, H.; Wong, R.S.; et al. Haematological and immunological data of Chinese children affected with coronavirus disease 2019. Data Brief 2020, $31,105953$. [CrossRef]

15. Tsao, H.S.; Chason, H.M.; Fearon, D.M. Immune Thrombocytopenia (ITP) in a Pediatric Patient Positive for SARS-CoV-2. Pediatrics 2020, 146, e20201419. [CrossRef] [PubMed]

16. Patel, P.; Chandrakasan, S.; Mickells, G.E.; Yildirim, I.; Kao, C.M.; Bennett, C.M. Severe Pediatric COVID-19 Presenting with Respiratory Failure and Severe Thrombocytopenia. Pediatrics 2020, 146, e20201437. [CrossRef] [PubMed] 
17. Rosenzweig, J.D.; McThenia, S.S.; Kaicker, S. SARS-CoV-2 infection in two pediatric patients with immune cytopenias: A single institution experience during the pandemic. Pediatr. Blood Cancer 2020, 67, e28503. [CrossRef]

18. Han, Y.N.; Feng, Z.W.; Sun, L.N.; Ren, X.X.; Wang, H.; Xue, Y.M.; Wang, Y.; Fang, Y. A comparative-Descriptive analysis of clinical characteristics in 2019-coronavirus-infected children and adults. J. Med. Virol. 2020, 92, 1596-1602. [CrossRef]

19. Yang, M.; Ng, M.H.; Li, C.K. Thrombocytopenia in patients with severe acute respiratory syndrome (review). Hematology 2005, 10, 101-105. [CrossRef]

20. Xu, P.; Zhou, Q.; Xu, J. Mechanism of thrombocytopenia in COVID-19 patients. Ann. Hematol. 2020, 99, 1205-1208. [CrossRef] [PubMed]

21. Mehta, P.; McAuley, D.F.; Brown, M.; Sanchez, E.; Tattersall, R.S.; Manson, J.J. COVID-19: Consider cytokine storm syndromes and immunosuppression. Lancet 2020, 395, 1033-1034. [CrossRef]

22. Yamada, T.; Wakabayashi, M.; Yamaji, T.; Chopra, N.; Mikami, T.; Miyashita, H.; Miyashita, S. Value of leukocytosis and elevated C-reactive protein in predicting severe coronavirus 2019 (COVID-19): A systematic review and meta-analysis. Clin. Chim. Acta 2020, 509, 235-243. [CrossRef] [PubMed]

23. Zhang, S.; Li, L.; Shen, A.; Chen, Y.; Qi, Z. Rational Use of Tocilizumab in the Treatment of Novel Coronavirus Pneumonia. Clin. Drug Investig. 2020, 40, 511-518. [CrossRef] [PubMed]

24. Yarali, N.; Akcabelen, Y.M.; Unal, Y.; Parlakay, A.N. Hematological parameters and peripheral blood morphologic abnormalities in children with COVID-19. Pediatr. Blood Cancer 2020, e28596. [CrossRef]

25. Hashemieh, M. Hematologic parameters of COVID-19: A review on alteration of hematologic laboratory findings. Int. J. Pediatr. 2020, 8, 11321-11929.

26. Chen, X.; Ling, J.; Mo, P.; Zhang, Y.; Jiang, Q.; Ma, Z.; Cao, Q.; Hu, W.; Zou, S.; Chen, L.; et al. Restoration of leukomonocyte counts is associated with viral clearance in COVID-19 hospitalized patients. Medrxiv 2020. [CrossRef]

27. Lu, X.; Zhang, L.; Du, H.; Zhang, J.; Li, Y.Y.; Qu, J.; Zhang, W.; Wang, Y.; Bao, S.; Li, Y.; et al. SARS-CoV-2 Infection in Children. N. Engl. J. Med. 2020, 382, 1663-1665. [CrossRef] [PubMed]

28. Henry, B.M.; Lippi, G.; Plebani, M. Laboratory abnormalities in children with novel coronavirus disease 2019. Clin. Chem. Lab. Med. 2020, 58, 1135-1138. [CrossRef]

29. Qiu, H.; Wu, J.; Hong, L.; Luo, Y.; Song, Q.; Chen, D. Clinical and epidemiological features of 36 children with coronavirus disease 2019 (COVID-19) in Zhejiang, China: An observational cohort study. Lancet Infect. Dis. 2020, 20, 689-696. [CrossRef]

30. Ma, H.; Hu, J.; Tian, J.; Zhou, X.; Li, H.; Laws, M.T.; Wesemann, L.D.; Zhu, B.; Chen, W.; Ramos, R.; et al. Visualizing the Novel Coronavirus (COVID-19) in Children: What we Learn from Patients at Wuhan Children's Hospital. 2020. Available online: https: / / ssrn.com/abstract=3550012 (accessed on 16 March 2020). [CrossRef]

31. Sun, D.; Li, H.; Lu, X.-X.; Xiao, H.; Ren, J.; Zhang, F.-R.; Liu, Z.-S. Clinical features of severe pediatric patients with coronavirus disease 2019 in Wuhan: A single center's observational study. World J. Pediatr. 2020, 16, 251-259. [CrossRef] [PubMed]

32. Kosmeri, C.; Koumpis, E.; Tsabouri, S.; Siomou, E.; Makis, A. Hematological manifestations of SARS-CoV-2 in children. Pediatr. Blood Cancer 2020, 67, e28745. [CrossRef] [PubMed]

33. Liu, J.; Liu, Y.; Xiang, P.; Pu, L.; Xiong, H.; Li, C.; Zhang, M.; Tan, J.; Xu, Y.; Song, R.; et al. Neutrophil-to-lymphocyte ratio predicts critical illness patients with 2019 coronavirus disease in the early stage. J. Transl. Med. 2020, 18, 206. [CrossRef] [PubMed]

34. Meena, J.; Yadav, J.; Saini, L.; Yadav, A.; Kumar, J. Clinical Features and Outcome of SARS-CoV-2 Infection in Children: A Systematic Review and Meta-analysis. Indian Pediatr. 2020, 57, 820-826. [CrossRef] [PubMed]

35. Tiwari, N.; Nath, D.; Madan, J.; Bajpai, P.; Madan, U.; Singh, S. Novel Insights into the Hematological Parameter Abnormalities in Pediatric COVID-19 Cases: Observation from A Preliminary Study of 11 Pediatric COVID-19 Cases in A Tertiary Care Center of North India. SJPM 2020, 5, 276-284. [CrossRef]

36. Lippi, G.; Mattiuzzi, C. Hemoglobin value may be decreased in patients with severe coronavirus disease 2019. Hematol. Transfus. Cell Ther. 2020, 42, 116-117. [CrossRef] [PubMed]

37. Liu, W.; Li, H. COVID-19: Attacks the 1-beta chain of hemo- globin and captures the porphyrin to inhibit human heme metabolism. ChemRxiv 2020. [CrossRef] 